\title{
Modeling predicted that tobacco control policies targeted at lower educated will reduce the differences in life expectancy.
}

Citation for published version (APA):

Bemelmans, W. J., van Lenthe, F. J., Hoogenveen, R., Kunst, A., Deeg, D. J., van den Brandt, P. A., Goldbohm, R. A., \& Verschuren, W. M. (2006). Modeling predicted that tobacco control policies targeted at lower educated will reduce the differences in life expectancy. Journal of Clinical Epidemiology, 59(9), 1002-1008. https://doi.org/10.1016/j.jclinepi.2006.02.008

Document status and date:

Published: 01/01/2006

DOI:

10.1016/j.jclinepi.2006.02.008

Document Version:

Publisher's PDF, also known as Version of record

Please check the document version of this publication:

- A submitted manuscript is the version of the article upon submission and before peer-review. There can be important differences between the submitted version and the official published version of record.

People interested in the research are advised to contact the author for the final version of the publication, or visit the DOI to the publisher's website.

- The final author version and the galley proof are versions of the publication after peer review.

- The final published version features the final layout of the paper including the volume, issue and page numbers.

Link to publication

\footnotetext{
General rights rights.

- You may freely distribute the URL identifying the publication in the public portal. please follow below link for the End User Agreement:

www.umlib.nl/taverne-license

Take down policy

If you believe that this document breaches copyright please contact us at:

repository@maastrichtuniversity.nl

providing details and we will investigate your claim.
}

Copyright and moral rights for the publications made accessible in the public portal are retained by the authors and/or other copyright owners and it is a condition of accessing publications that users recognise and abide by the legal requirements associated with these

- Users may download and print one copy of any publication from the public portal for the purpose of private study or research.

- You may not further distribute the material or use it for any profit-making activity or commercial gain

If the publication is distributed under the terms of Article 25fa of the Dutch Copyright Act, indicated by the "Taverne" license above, 


\title{
Modeling predicted that tobacco control policies targeted at lower educated will reduce the differences in life expectancy
}

\author{
W.J.E. Bemelmans ${ }^{\mathrm{a}, *}$, F. van Lenthe ${ }^{\mathrm{b}}$, R. Hoogenveen ${ }^{\mathrm{a}}$, A. Kunst ${ }^{\mathrm{b}}$, D.J.H. Deeg ${ }^{\mathrm{c}}$, \\ P.A. van den Brandt ${ }^{\mathrm{d}}$, R.A. Goldbohm ${ }^{\mathrm{e}}$, W.M.M. Verschuren ${ }^{\mathrm{a}}$ \\ ${ }^{\mathrm{a}}$ National Institute for Public Health and the Environment, Centre for Prevention and Health Services Research, P.O. Box 1, \\ Bilthoven 3720 BA, The Netherlands \\ ${ }^{\mathrm{b}}$ Erasmus MC, University Medical Center Rotterdam, department of Public Health, Rotterdam, The Netherlands \\ ${ }^{\mathrm{c}} \mathrm{VU}$ University Medical Center, Institute for Research in Extramural Medicine, Amsterdam, The Netherlands \\ ${ }^{\mathrm{d}}$ Maastricht University, Department of Epidemiology, Maastricht, The Netherlands \\ ${ }^{\mathrm{e}}$ TNO Quality of Life, department of Food and Chemical Risk Analysis, Zeist, The Netherlands
}

Accepted 27 February 2006

\begin{abstract}
Background and Objective: To estimate the effects of reducing the prevalence of smoking in lower educated groups on educational differences in life expectancy.

Methods: A dynamic Markov-type multistate transition model estimated the effects on life expectancy of two scenarios. A "maximum scenario" where educational differences in prevalence of smoking disappear immediately, and a "policy target-scenario" where difference in prevalence of smoking is halved over a 20 -year period. The two scenarios were compared to a reference scenario, where smoking prevalences do not change. Five Dutch cohort studies, involving over 67,000 participants aged 20 to 90 years, provided relative mortality risks by educational level, and smoking habits were assessed using national data of more than 120,000 persons.

Results: In the reference scenario, the difference in life expectancy at age 40 between highest and lowest educated groups was 5.1 years for men and 2.7 years for women. In the "maximum scenario" these differences were reduced to 3.6 years for men and 1.7 years for women (reduction $\approx 30 \%$ ), and in the "policy target-scenario" differences were 4.7 years for men and 2.4 years for women (reduction $\approx 10 \%$ ).

Conclusion: Theoretically, educational differences in life expectancy would be reduced by $30 \%$ at maximum, if variations in smoking prevalence were eliminated completely. In practice, tobacco control policies that are targeted at the lower educated may reduce the differences in life expectancy by approximately 10\%. (C) 2006 Elsevier Inc. All rights reserved.
\end{abstract}

Keywords: Educational differences; Life expectancy; Modeling; Mortality; Smoking

\section{Introduction}

A lower level of education is associated with increased overall and coronary heart disease mortality in many countries [1,2]. Among the factors that contribute to the higher mortality rates are increased prevalences of behavioral risk factors, such as smoking, in groups with a lower socioeconomic status (SES) [2]. In general, smoking prevalences are one to two times as high in lower educated people, especially in younger age categories [3]. Large cohort studies showed that about 20 to $60 \%$ of the excess mortality risk in lower educated persons is explained statistically by smoking or other health-related behaviors [4].

\footnotetext{
* Corresponding author: Tel.: +3130274 4297; fax +31 302744407 .

E-mail address: wanda.bemelmans@rivm.nl (W.J.E. Bemelmans).
}

Reducing inequalities in health is a priority of health policy in several countries. It is expected that inequality in health can be reduced when health promotion, for example to reduce smoking, is effectively targeted at lower educated groups. A Dutch governmental committee formulated a quantitative policy target on reducing socioeconomic differences in smoking, namely that the difference should be halved over a 20-year period [5]. In general, limited data are available about the effects of health promotional activities in lower educated groups. Scientific intervention studies, designed to investigate this, would require a large population or a long period of follow-up and are therefore expensive. An alternative approach is to use models for estimating the effects of different scenarios [6].

In this context it is worthwile to estimate the effects on the socioeconomic gradient in mortality when variation in smoking habits is reduced. Therefore, we used a dynamic 
Markov-type multistate transition model, called the Chronic Disease Model (CDM). The CDM has been used before in Dutch policy documents for the Ministry of Health [7]. The present article describes the effects of two scenarios. A "maximum scenario" where differences in smoking habits between educational groups disappear immediately, and a "policy target-scenario" where differences in smoking habits are halved over a 20-year period [5]. The effects of these two scenarios are compared to a "reference scenario," where smoking prevalences do not change. The main objective is to estimate the effects on differences in life expectancy and mortality rates between highest and lowest educated groups.

\section{Methods}

\subsection{Description of the model}

The effects of the two smoking interventions were estimated by using a dynamic Markov-type multistate transition model, called the CDM, which is described elsewhere, including an appendix with mathematical details $[8,9]$. In line with the main objective of this manuscript, the further description of the CDM is focused on smoking and mortality. In short, the dynamic CDM describes the development over time of demography, smoking prevalence, and mortality in the Dutch population, and is developed to estimate the effects of (theoretic) scenarios. For each person several classes or "multiple states" are defined, such as age, educational level, and smoking habit (three classes: current, former, never smoker). The model contains probabilities of changing from one class to another, the so-called transition rates. The transition rate to the class "death," which simulates that a person dies, is dependent on age, educational level, and smoking habit. For example, at a given age and educational level, a "current smoker" has a higher probability of dying than a "never smoker."

The CDM is a Markov-type model, which means that for each class the future state is dependent of the previous state, but not on states in the further past. A second assumption is that relative mortality risks for smoking and educational level are multiplicative, and hence, no interaction occurs on a log scale. Finally, model parameters are time constant, which means that no external time trend is assumed.

The main CDM parameters are initial prevalence and transition rates for smoking habits, overall mortality rates, relative mortality risks by educational groups, adjusted for smoking, and relative mortality risks for current and former smokers. All parameters were specified according to age and educational level, except for relative mortality risks for current and former smokers. These were assumed to be equal in all educational groups, and were based on extensive literature research. For "current smoking" relative mortality risks ranged from 1.4 to 2.5 in men, and for women from 1.6 to 2.3, depending on age. For former smoking relative mortality risks ranged from 1.2 to 1.3 in men and from 1.1 to 1.5 in women. These risks are documented in an RIVM report for internal use. In total, 27 cohorts are involved including, for example, the CPS I and II cohorts, the British Doctors study, NHANES, and various Dutch cohorts.

\subsection{Model parameters specified by educational level}

SES was operationally defined as the highest educational level achieved, which correlates well with other SES indicators in The Netherlands [10]. Four educational categories were defined: lowest (primary school), low (lower vocational and lower general secondary school), intermediate (intermediate vocational and intermediate/higher general secondary school), and high (higher vocational school and university). Demographic data and the overall distribution of educational level were obtained from Statistics Netherlands (period 1996 to 2000). The percentage with the lowest educational level varied from $8 \%$ in 20-29-year-old age groups to $35 \%$ for men and $57 \%$ for women in $70-79$-yearold age groups. The percentages with the highest educational level varied from $20 \%$ in the 20-29-year-old age groups to $14 \%$ for men and $6 \%$ for women in the 70-79year-old age groups.

Baseline prevalences of current, former and never smokers, stratified by educational level, were provided by the Dutch Foundation on Smoking and Health (Stivoro), Statistics Netherlands, and the Second Dutch National Survey of General Practice (DNSGP2) [11] (period 1996 to 2001). The average smoking prevalence of these three sources was calculated, weighted by number of participants, and stratified within age categories of 10 years. The data involved more than 120,000 participants aged 20 to 80 years. Transition rates for changing smoking habits were derived from the prevalence data. The probability of starting smoking appeared to be 1.6 times higher, and the probability of stopping smoking about 2.0 times smaller in the lowest educated group compared to the highest educated group, in all age categories. Furthermore, based on previous research we assumed that nobody starts smoking for the first time after the age of 35 [12]. The probability of starting smoking again, after quiting for some time, was assumed to be independent of educational level.

Relative mortality risks by educational level were provided by the GLOBE study [13], the Monitoring Project on Cardiovascular Risk Factors ("Peilstationsproject") [14], the Longitudinal Aging Study Amsterdam (LASA study) [15], Rotterdam study (ERGO) [16], and a subcohort of the Netherlands Cohort Study on Diet and Cancer (NLCS) [17]. Table 1 presents basic characteristics of these cohort studies. In total, 31,565 men and 36,262 women aged 20 to 90 years were followed for on average 9 years. 
Table 1

Characteristics of the five cohort studies, used in the pooled analyses

\begin{tabular}{lllll}
\hline & PEIL & GLOBE & LASA & NLCS \\
\hline Year baseline & $1987-1992$ & 1991 & 1992 & $1990-1993$ \\
Period of follow-up (year) & 10 & 7 & 1986 \\
Age baseline (range) & $20-59$ & $15-75$ & $54-89$ & 10 \\
Number of participants $^{\text {a }}$ & 39,483 & 14,086 & 5,664 & 7,152 \\
\hline
\end{tabular}

Abbrevations: PEIL, monitoring project on cardiovascular risk factors ("Peilstationsproject") [14], GLOBE study [13]; LASA, Longitudinal Aging Study Amsterdam [15]; Rotterdam study [16]; NLCS, subcohort of the Netherlands Cohort Study on Diet and Cancer [17].

a The number of participants of which data are available about smoking habits and educational level.

\subsection{Definition of scenarios}

The effects of two intervention scenarios were estimated. First, a theoretic scenario where differences in smoking habits between educational groups disappear immediately and completely ("maximum scenario"). In this scenario, the lowest educated group is assumed to acquire the prevalences and transition rates that the highest educated group displays at baseline. It shows the maximum extent to which differences in life expectancy can be reduced by eliminating socioeconomic differences in smoking.

In the second intervention scenario we simulated that differences in smoking habits halved during a 20-year period ("policy target scenario"). A Dutch government advisory committee formulated this target as following: "the difference in smoking between those with lower and those with higher education should be halved, by decreasing the percentage of smokers among those with only primary school education from over $38 \%$ in 1998 to $\leqslant 32 \%$ by 2020" [5]. This scenario was operationally defined by changing the transition rates in the CDM, to simulate that more "present smokers" became "former smokers" among lowest educated persons. The effects of the two scenarios are compared to a "reference scenario" where smoking habits remain the same in all educational groups.

\subsection{Sensitivity analyses}

The main outcome measures include the difference in mortality rates between lowest and highest educated groups. To gain insight in the sensitivity of the CDM we assessed the relative change of this outcome measure resulting from relative changes in specific model input variables. The analyses were performed with a $10 \%$ larger inequality between educational groups in initial smoking prevalences, in probabilities of stopping smoking, and in relative all-cause mortality risks, and subsequently, the effects on differences in mortality rates were evaluated.

\subsection{Statistics and calculation of life expectancy}

In each of the five cohort studies, relative mortality risks by educational level were assessed by Cox regression analysis. Adjustments for smoking were made by including dummy variables for present smoking and former smoking. The analyses only included participants with complete data on survival status, smoking habit, and educational level. The relative risks (RRs) of the separate cohort studies were pooled using a random effects model, as described elsewhere [18]. The pooled relative risks were used for the modeling.

The (differences in) life expectancy were calculated by running the CDM for such a long period that the baseline population, as present in the different states of the CDM, had "died," while aggregating all years lived in the the different scenarios. In general, differences in life expectancy between educational groups were caused by different smoking habits at baseline (see Table 2) and by different mortality risks by educational level, independent of smoking (see

Table 2

Prevalence of current smoking (prev) and rate ratio ${ }^{\mathrm{a}}$ by educational group, gender, and age, during the period of 1996-2001 in The Netherlands ${ }^{\mathrm{b}}$

\begin{tabular}{|c|c|c|c|c|c|c|c|c|c|c|c|c|}
\hline & \multicolumn{2}{|c|}{$20-29$} & \multicolumn{2}{|c|}{$30-39$} & \multicolumn{2}{|c|}{$40-49$} & \multicolumn{2}{|c|}{$50-59$} & \multicolumn{2}{|c|}{$60-69$} & \multicolumn{2}{|c|}{$70-79$} \\
\hline & Prev & rate ratio & prev & rate ratio & prev & rate ratio & prev & rate ratio & prev & rate ratio & prev & rate ratio \\
\hline \multicolumn{13}{|l|}{ Men } \\
\hline Lowest & 49.0 & 1.5 & 55.6 & 1.8 & 54.4 & 1.7 & 46.9 & 1.5 & 35.0 & 1.6 & 30.0 & 1.7 \\
\hline Low & 47.1 & 1.4 & 49.0 & 1.6 & 46.6 & 1.5 & 37.6 & 1.2 & 30.3 & 1.4 & 24.4 & 1.4 \\
\hline Medium & 41.2 & 1.2 & 38.8 & 1.3 & 39.8 & 1.2 & 35.6 & 1.1 & 24.9 & 1.1 & 19.7 & 1.1 \\
\hline High & 33.3 & 1.0 & 30.2 & 1.0 & 32.1 & 1.0 & 31.8 & 1.0 & 22.4 & 1.0 & 17.6 & 1.0 \\
\hline \multicolumn{13}{|l|}{ Women } \\
\hline Lowest & 39.5 & 1.5 & 51.2 & 2.2 & 48.2 & 1.8 & 37.7 & 1.6 & 23.0 & 1.5 & 10.5 & 1.6 \\
\hline Low & 38.8 & 1.4 & 43.4 & 1.9 & 41.6 & 1.5 & 29.7 & 1.3 & 20.5 & 1.3 & 11.3 & 1.7 \\
\hline Medium & 33.3 & 1.2 & 32.5 & 1.4 & 36.5 & 1.3 & 27.3 & 1.2 & 16.8 & 1.1 & 12.9 & 1.9 \\
\hline High & 27.1 & 1.0 & 23.2 & 1.0 & 27.1 & 1.0 & 22.9 & 1.0 & 15.8 & 1.0 & 6.7 & 1.0 \\
\hline
\end{tabular}

${ }^{\text {a }}$ Rate ratio: percentage of current smokers in the lowest educated group divided by the percentage of current smokers in the highest educated group.

b Sources: weighted average of Stivoro, Statistics Netherlands, DNSGP2; total $n=62.609$ men and 65.571 women. 
Table 3). The first has an effect on mortality because the CDM contains relative mortality risks for smoking classes (see "description of the model").

\section{Results}

\subsection{Smoking habits by educational level}

Table 2 shows the prevalences of current smokers among educational groups. The proportion of current smokers in the lowest educated group divided by the proportion in the highest educated group (= rate ratio) ranges from 1.5 to 1.8 in men, and from 1.5 to 2.2 in women. For never smokers, the rate ratio ranges from 0.5 to 0.8 in men and from 0.6 to 1.0 in women until the age of 70. In women older than 70 years the proportion of never smokers is higher, rather than lower, in the lowest educated group (73.1\%), than in the highest educated group (65.6\%) (data not shown).

\subsection{Relative mortality risks}

The unadjusted relative mortality risk in the lowest educated group compared to the highest educated group is 1.57 $(95 \% \mathrm{CI}=1.36,1.82)$ in men and $1.27(95 \% \mathrm{CI}=1.01$, 1.59 ) in women (Table 3 ). The mortality risk of lowest educated people tends to be increased in all age categories, but the least pronounced among 70-79-year-old women (unadjusted $\mathrm{RR}=1.05$ ).
Statistical adjustment for smoking reduces the excess mortality by $30 \%$ in $40-50$-year-old age groups, by $30-$ $40 \%$ in $50-60$-year-old age groups, and by $20-30 \%$ in men older than 60 years. In older women, statistical adjustment for smoking had no effect. Overall, smoking adjusted relative mortality risks are $1.41(95 \% \mathrm{CI}=1.23,1.62)$ for men and $1.20(95 \% \mathrm{CI}=0.96,1.51)$ for women (Table 3$)$.

\subsection{Modeling of scenarios}

\subsubsection{Effects on mortality rates among lowest educated persons}

Table 4 shows mortality rates (number of deaths per 100 persons) after 10 years, in the year 2015, among lowest and highest educated persons in the reference scenario, and for the lowest educated persons also in the "maximum" and "policy target" scenarios. The effect on mortality is largest in lowest educated men aged 40 to 50 years. After 10 years, in the year 2015, the mortality rate in this subpopulation is estimated to be $0.70 / 100$ in the reference scenario, $0.57 / 100$ in the maximum scenario, and $0.67 / 100$ in the "policy target" scenario (Table 4). In the year 2015, in different age groups approximately $0-19 \%$ of male deaths and $0-16 \%$ of female deaths among the lowest educated would be prevented in the "maximum scenario," when compared to the reference scenario. With the "policy target scenario," the number of prevented deaths would be approximately 0$6 \%$ for both men and women (Table 4 ).

Table 3

Relative risk $(95 \% \mathrm{CI})$ of mortality by educational level, unadjusted and adjusted for smoking for the total population and stratified for age $\mathrm{e}^{\mathrm{a}}$

\begin{tabular}{llll}
\hline & Educational level ${ }^{\mathrm{b}}$ & & \\
\cline { 2 - 4 } & Lowest & Low & Medium \\
\hline Men & & & \\
40-49 Unadj & $1.83(0.11-29.2)$ & $1.19(0.03-46.2)$ & $0.89(0.04-21.6)$ \\
Adj & $1.58(0.10-25.3)$ & $1.12(0.05-26.0)$ & $0.86(0.03-21.3)$ \\
$50-59$ Unadj & $1.89(1.32-2.72)$ & $1.46(1.01-2.10)$ & $1.53(1.06-2.21)$ \\
Adj & $1.59(1.10-2.29)$ & $1.30(0.90-1.87)$ & $1.41(0.98-2.04)$ \\
60-69 Unadj & $1.39(0.99-1.94)$ & $1.14(0.81-1.61)$ & $1.14(0.81-1.59)$ \\
Adj & $1.28(0.92-1.79)$ & $1.10(0.78-1.56)$ & $1.11(0.79-1.55)$ \\
$70-79$ Unadj & $1.41(0.70-2.84)$ & $1.05(0.36-3.09)$ & $1.04(0.55-1.99)$ \\
Adj & $1.32(0.60-2.60)$ & $1.01(0.28-1.32)$ & $1.05(0.55-2.00)$ \\
Overall ${ }^{\mathrm{c}}$ Unadj & $1.57(1.36-1.82)$ & $1.23(1.04-1.46)$ & $1.19(1.03-1.37)$ \\
Adj & $1.41(1.23-1.62)$ & $1.15(0.96-1.38)$ & $1.15(0.99-1.32)$ \\
Women & & & \\
40-49 Unadj & $1.33(0.05-37.1)$ & $1.04(0.05-23.2)$ & $0.88(0.01-76.6)$ \\
Adj & $1.23(0.04-41.0)$ & $0.99(0.04-26.4)$ & $0.86(0.01-74.5)$ \\
50-59 Unadj & $1.28(0.75-2.21)$ & $1.27(0.56-2.86)$ & $1.14(0.59-2.21)$ \\
Adj & $1.17(0.68-2.02)$ & $1.20(0.54-2.70)$ & $1.12(0.58-2.17)$ \\
60-69 Unadj & $1.26(0.64-2.49)$ & $1.04(0.51-2.12)$ & $0.99(0.48-2.05)$ \\
Adj & $1.29(0.65-2.54)$ & $1.06(0.52-2.16)$ & $1.00(0.48-2.07)$ \\
$70-79$ Unadj & $1.05(0.43-2.55)$ & $0.76(0.30-1.89)$ & $0.80(0.30-2.14)$ \\
Adj & $1.02(0.42-2.48)$ & $0.73(0.29-1.82)$ & $0.78(0.29-2.10)$ \\
Overall ${ }^{c}$ Unadj & $1.27(1.01-1.59)$ & $0.98(0.78-1.23)$ & $0.95(0.75-1.19)$ \\
Adj & $1.20(0.96-1.51)$ & & $0.96(0.74-1.27)$ \\
\hline & & &
\end{tabular}

\footnotetext{
${ }^{a}$ Pooled analyses of five Dutch cohort studies.

b Reference category is high educational level.

c Population of 30 to 80 years old; CI, confidence interval.
} 
Table 4

Mortality rates in the year 2015 for the highest and lowest educated groups in the different scenarios ( $n$ deaths/100 persons)

\begin{tabular}{|c|c|c|c|c|c|c|}
\hline & $20-29$ & $30-39$ & $40-49$ & $50-59$ & $60-69$ & $70-79$ \\
\hline \multicolumn{7}{|l|}{ Men } \\
\hline \multicolumn{7}{|l|}{ Reference scenario } \\
\hline High education & 0.09 & 0.14 & 0.42 & 1.25 & 3.07 & 8.31 \\
\hline Lowest education & 0.16 & 0.27 & 0.70 & 1.86 & 4.02 & 10.57 \\
\hline \multicolumn{7}{|l|}{ Maximum scenario } \\
\hline Lowest education $^{\mathrm{a}}$ & 0.16 & 0.23 & 0.57 & 1.61 & 3.67 & 10.05 \\
\hline Prevented $^{\mathrm{b}}(\%)$ & $0 \%$ & $15 \%$ & $19 \%$ & $13 \%$ & $9 \%$ & $5 \%$ \\
\hline Reduction difference $^{\mathrm{c}}(\%)$ & $0 \%$ & $31 \%$ & $46 \%$ & $41 \%$ & $37 \%$ & $23 \%$ \\
\hline \multicolumn{7}{|l|}{ Policy target scenario } \\
\hline Lowest education $^{\mathrm{a}}$ & 0.16 & 0.26 & 0.67 & 1.80 & 3.93 & 10.42 \\
\hline Prevented $^{\mathrm{b}}(\%)$ & $0 \%$ & $4 \%$ & $4 \%$ & $3 \%$ & $2 \%$ & $1 \%$ \\
\hline Reduction difference $^{\mathrm{c}}(\%)$ & $0 \%$ & $8 \%$ & $11 \%$ & $10 \%$ & $9 \%$ & $7 \%$ \\
\hline \multicolumn{7}{|l|}{ Women } \\
\hline \multicolumn{7}{|l|}{ Reference scenario } \\
\hline High education & 0.08 & 0.13 & 0.29 & 0.73 & 1.84 & 5.61 \\
\hline Lowest education & 0.10 & 0.18 & 0.43 & 0.96 & 2.39 & 6.23 \\
\hline \multicolumn{7}{|l|}{ Maximum scenario } \\
\hline Lowest education $^{\mathrm{a}}$ & 0.10 & 0.16 & 0.36 & 0.85 & 2.22 & 6.12 \\
\hline Prevented $^{\mathrm{b}}(\%)$ & $0 \%$ & $11 \%$ & $16 \%$ & $11 \%$ & $7 \%$ & $2 \%$ \\
\hline Reduction difference $^{\mathrm{c}}(\%)$ & $0 \%$ & $40 \%$ & $50 \%$ & $48 \%$ & $31 \%$ & $18 \%$ \\
\hline \multicolumn{7}{|l|}{ Policy target scenario } \\
\hline Lowest education $^{\mathrm{a}}$ & 0.10 & 0.17 & 0.41 & 0.94 & 2.35 & 6.19 \\
\hline Prevented $^{\mathrm{b}}(\%)$ & $0 \%$ & $6 \%$ & $5 \%$ & $2 \%$ & $2 \%$ & $1 \%$ \\
\hline Reduction difference $^{\mathrm{c}}(\%)$ & $0 \%$ & $20 \%$ & $14 \%$ & $9 \%$ & $7 \%$ & $6 \%$ \\
\hline
\end{tabular}

a Mortality rates are presented for the lowest educated only, because these rates for the highest educated are equal to the reference scenario.

b The percentage of deaths among the lowest educated that would be prevented after 10 years, in the year 2015 , compared to the reference scenario.

c The effect on the difference in mortality rates between highest and lowest educated groups.

\subsubsection{Effects on differences in mortality rates and life expectancy}

Differences in mortality rates between highest and lowest educational groups would be reduced by no more than $50 \%$ in 30-60-year-old persons, by approximately onethird in the 60-69-year-old, and by approximately one-fifth in 70-80-year-old age groups in the "maximum scenario" (Table 4 "reduction difference").

Figure 1 shows the effects on life expectancy. In the "reference scenario" the difference in life expectancy, at age 40, between lowest and highest educated groups is 5.1 years for men and 2.7 years for women. With the

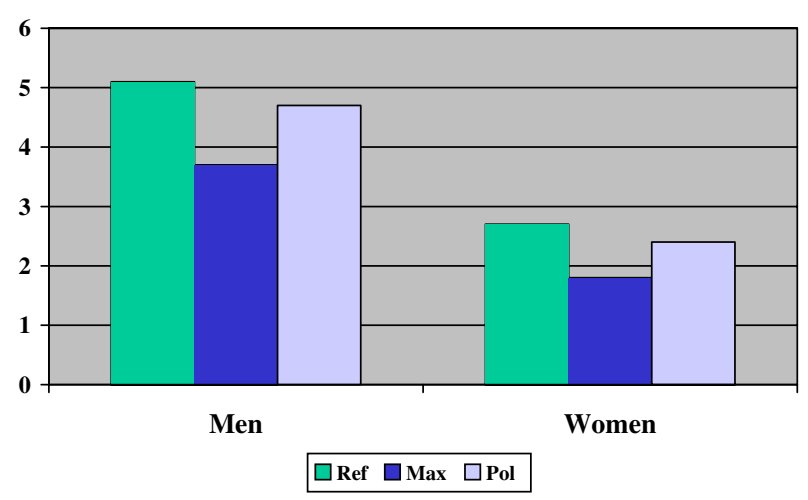

Fig. 1. Differences in life expectancy at age 40 between highest and lowest educated groups for the reference scenario (ref) the "maximum scenario" (max), and "policy target-scenario" (pol), for men and women. "maximum scenario" gains in life expectancy would be 1.5 and 1.0 years in lowest educated men and women, respectively. Hence, the difference in life expectancy between the lowest and highest educational level would be reduced to 3.6 years for men and 1.7 years for women (reduction of $30 \%)$. With the "policy target-scenario" the difference in life expectancy between the lowest and highest educational level would be reduced to 4.7 years for men and 2.4 years for women (reduction of 10\%).

\subsection{Sensitivity analyses}

The analyses were performed also with a $10 \%$ larger difference between the highest and lowest educated group in initial smoking prevalence, in probability of stopping smoking, and in relative mortality risks. The CDM appeared to be most sensitive for differences in initial smoking prevalences. When the rate ratio would be $10 \%$ larger, the absolute number of deaths that would be prevented in the lowest educated group is 7\% larger in men and 16\% larger in women, according to the "maximum scenario."

\section{Discussion}

The life expectancy at age 40 was estimated to be 5.1 and 2.7 years shorter among lowest educated men and women, respectively, compared to highest educated persons. This is comparable to Finland, where differences in 
life expectancy at age 25 were estimated to be 6.3 years for men and 3.2 years for women [19]. We showed that, theoretically, differences in life expectancy can be reduced by one-third, when smoking habits would become equal immediately. However, this scenario cannot be achieved in reality. The "policy target" scenario showed that differences in mortality rates between educational groups would be reduced by approximately $10 \%$.

During the modeling of the scenarios several assumptions were made, which simplified the situation. Therefore, the present results, just like other modeling study results, should be interpreted with caution as an indication of the effects. We assumed that the relative mortality risk for smoking is equal among educational groups. Previous research suggested an interaction effect because lower educated heavy smokers had higher lung cancer mortality risks than higher educated smokers [20]. However, similar Danish research underpinned our assumption [21]. The assumption seems therefore defensible, in particular because sensitivity analyses showed that the effects of the relative risks on mortality were small. Another assumption was that persons who quit smoking immediately received the relative mortality risk of a former smoker. This means that the CDM contains no "lag time," and the effects of the scenarios are somewhat overestimated.

In general, accuracy of modeling outcomes depends on the estimation of the main model parameters. Inevitably, the model parameters are influenced by measurement errors and residual confounding, as is the case in all modeling studies. The present study is based on large data sources, but nevertheless, confidence intervals of, for example, the relative mortality risks by educational level were wide (see Table 3). Furthermore, the cohort studies started around 1986 to 1993 , and in this period the mortality risk was not increased in 70-79-year-old lowest educated women. This may be an underestimation of the "real" situation in elderly women in the year 2000, and hence, also an underestimation of the effects of the scenarios. In this respect we emphasize that baseline smoking habits were based on recent data (1996-2001). We modeled "into the future" and the future socioeconomic differences in mortality are derived from differences in smoking habits (concerning smoking related mortality) and from increased mortality in lower educated groups due to other mechanisms. The latter risk is derived from the cohorts (e.g., the smoking adjusted relative risks in Table 3 ). The underlying causes of this excess risk can be due to lower income/ access to care, inheritance or psychosocial factors. We acknowledge that it is not plausible that the RR in the 7079-year-old from the cohorts, who were born between 1910 and 1930, will be the same for this age categorie in the future. However, the smoking adjusted RRs were quite similar across age categories (despite probable differences in underlying mechanisms). Furthermore, the assumption behind taking this risk is least plausible for the elderly, and fortunately, this is also the age group that weights less in estimating gains in life expectancy.
Data from Finland, England, and France indicate that relative inequality in mortality widened between the beginning of the eighties and the beginning of the nineties [2224], and may widen further in the future [3]. An advantage of our methodology is that these changes in relative socioeconomic inequalities in mortality in the last decade are incorporated at least partially (e.g., the smoking related risk).

We found a pooled relative risk for total mortality of 1.41 for lowest educated men and 1.20 for women, when adjusted for smoking. These relative risks are comparable to those as found in seven other countries. RR for men ranged from 1.25 (Norway) to 1.78 (Hungary), and for women from 1.09 (Czech Republic) to 1.31 (USA and Estonia) [25]. Also, the effects of adjustment for smoking are comparable to other studies. The British Regional Heart study found that adjustment for smoking reduced the excess mortality risk by almost $40 \%$ in 40-60-year-old men [26]. The Kuopio Ischemic Heart Disease Risk Factor Study found a reduction of 35\%, when adjusted for smoking, alcohol consumption, and physical activity [27]. Furthermore, similar effects were found when mortality risks of smoking related diseases are adjusted for smoking, such as ischemic heart disease [12] or lung cancer [28]. So, the extent to which differences in mortality risks are explained by smoking habits seems to be quite robust, and this supports generalisation of our findings to other populations.

In view of the large differences in smoking habits between educational groups, the effects on life expectancy may be considered relatively small. However, especially in younger ages, the excess mortality risks in lower educated people are not due primarily to smoking related diseases. Blane et al. calculated that the "years of potential life lost" in lower educated people due to violence and external causes are comparable with those due to ischaemic heart disease. Hence, they argued that individual health behavior is of comparatively small importance to the socioeconomic differences in health [29]. On the other hand, in middle-aged persons smoking-related diseases are important causes of death. Therefore, the short-term effects of smoking cessation of lower educated persons are largest among middle-aged people, as was supported by our results (Table 4).

Reducing inequalities in health is a priority of health policy. A Dutch governmental committee formulated an overall target to reduce the differences in health by $25 \%$, for example, by promoting smoking cessation among the lower educated. It should be stressed that encouraging lower educated people to stop smoking requires a specific approach. As a result of general health publicity, socioeconomic differences sometimes even widened [30,31]. Raising taxes, restriction of smoking at work, and nicotin replacement therapy may be more succesfull [32], but generally intervention results stratified for socioeconomic status are limited [33]. It has been argued that a wide spectrum of interventions is needed, besides health promotion, 
which work on disadvantages associated with a lower SES, such as poor housing [34]. This is congruent with our conclusion that antismoking policy can contribute to decreasing the socioeconomic differences in mortality (by approximately 10\%), but that the overall target of lowering these differences by $25 \%$ cannot be achieved by antismoking policy only.

\section{Acknowledgments}

We thank dr Gert Westert for providing data from the Second Dutch National Survey of General Practice, dr Jacqueline Witteman (Erasmus MC, University Medical Center Rotterdam) for providing data from the Rotterdam Elderly Study, Dr. Jeanne van Loon and Dr. Susan Picavet for assistance during the data collection and management, Dr. Fons vd Lucht for advices on socioeconomic health matters, and Dr. Hendriek Boshuizen for statistical advice. F.v.L. is supported by a grant from the Netherlands Organisation for Scientific Research (NWO grant number 904-66-104). The authors declare that there are no competing interests.

\section{References}

[1] Kunst AE, Mackenbach JP. The size of mortality differences associated with educational level in nine industrialized countries. Am J Public Health 1994;84:932-7.

[2] Mackenbach JP, Cavelaars AEJM, Kunst AE, Groenhof F, the EU working group on socioeconomic inequalities in health. Socioeconomic inequalities in cardiovascular disease mortality. An international study. Eur Heart J 2000;21:1141-51.

[3] Huisman M, Kunst AE, Mackenbach JP. Educational inequalities in smoking among men and women aged 16 years and older in 11 European countries. Tob Control 2005;14:106-13.

[4] Bucher HC, Ragland DR. Socioeconomic indicators and mortality from coronary heart disease and cancer: a 22-year follow-up of middle-aged men. Am J Public Health 1995;85:1231-6.

[5] Mackenbach JP, Stronks K. A strategy for tackling health inequalities in the Netherlands. Br Med J 2002;325:1029-32.

[6] Gunning-Schepers LJ. Models: instruments for evidence based policy. J Epidemiol Community Health 1999;53:263.

[7] Gezondheid op Koers? Volksgezondheid Toekomst Verkenning 2002. Report no 270551001 [in Dutch]. Rijksinstituut voor Volksgezondheid en Milieu (RIVM), Bilthoven; 2002.

[8] Feenstra TL, Hamberg-van Reenen HH, Hoogenveen RT, Rutten-van Mölken MPMH. Cost-effectiveness of face-to-face smoking cessation interventions: a dynamic modeling study. Value Health 2005;8:178-90.

[9] Feenstra TL, van Genugten ML, Hoogenveen RT, et al. The impact of aging and smoking on the future burden of chronic obstructive pulmonary disease: a model analysis in The Netherlands. Am J Respir Crit Care Med 2001;164:590-6.

[10] van Berkel-van Schaik AB, Tax B. Towards a standard operationalisation of socioeconomic status for epidemiological and socio-medical research. [in Dutch]. Rijswijk: ministerie van WVC; 1990.

[11] Westert GP, Schellevis FG, Bakker de DH, Groenewegen PP, Bensing JM, Zee van der J. Monitoring health inequalities through General Practice: the Second Dutch National Survey of General Practice. Eur J Public Health 2005;15:59-65.

[12] Etter JF, Perneger TV, Ronchi A. Distribution of smokers by stage: international comparison and association with smoking prevalence. Prev Med 1997;26:580-5.
[13] Lenthe van FJ, Gevers E, Joung IMA, Bosma H, Mackenbach JP. Material and behavioral factors in the explanation of educational differences in incidence of acute myocardial infarction: The Globe Study. Ann Epidemiol 2002;12:535-42.

[14] Verschuren WMM, van Leer EM, Blokstra A, Seidell JC, Smit HA, Bueno de Mesquita HB, Obermann-de Boer GL, Kromhout D. Cardiovascular disease risk factors in the Netherlands. Neth J Cardiol 1993;6:205-10.

[15] Visser M, Launer LJ, Deurenberg P, Deeg DJ. Past and current smoking in relation to body fat distribution in older men and women. J Gerontol A Biol Sci Med Sci 1999;54:M293-8.

[16] Hofman A, Grobbee DE, de Jong PT, van den Ouweland FA. Determinants of disease and disability in the elderly: the Rotterdam elderly study. Eur J Epidemiol 1991;7:403-22.

[17] van den Brandt PA, Goldbohm RA, van 't Veer P, Volovics A, Hermus RJ, Sturmans F. A large-scale prospective cohort study on diet and cancer in The Netherlands. J Clin Epidemiol 1990;43(3):285-95.

[18] Houwelingen van HC, Arends LR, Stijnen T. Tutorial in biostatistics. Advanced methods in meta-analysis: multivariate approach and meta-regression. Stat Med 2002;21:589-624.

[19] Valkonen T, Sihvonen AP, Lahelma E. Health expectancy by level of education in Finland. Soc Sci Med 1997;44:801-8.

[20] Martikainen P, Lahelma E, Ripatti S, Albanes D, Virtamo J. Educational differences in lung cancer mortality in male smokers. Int J Epidemiol 2001;30:264-7.

[21] Bronnum-Hansen H, Juel K. Impact of smoking on the social gradient in health expectancy in Denmark. J Epidemiol Community Health 2004;58:604-10.

[22] Valkonen T. Trends in regional and socio economic mortality differentials in Finland. Int J Health Sci 1993;3:157-66.

[23] Lang T, Ducimetière P. Premature cardiovascular mortality in France: divergent evolution between social categories from 1970 to 1990. Int J Epidemiol 1995;24:331-9.

[24] Phillimore P, Beattie A, Townsend P. Widening inequality of health in northern England 1981-91. Br Med J 1994;308:1125-8.

[25] Mackenbach JP, Kunst AE, Groenhof F, Borgan JK, Costa G, Faggiano F, Józan P, Leinsalu M, Martikainen P, Rychtarikova J, Valkonen T. Socioeconomic inequalities in mortality among women and among men: an international study. Am J Public Health 1999;89:1800-6.

[26] Wannamethee SG, Shaper AG. Socioeconomic status within social class and mortality: a prospective study in middle-aged British men. Int J Epidemiol 1997;26:532-41.

[27] Lynch JW, Kaplan GA, Cohen RD, Tuomilehto J, Salonen JT. Do cardiovascular risk factors explain the relation between socioeconomic status, risk of all cause mortality, cardiovascular mortality, and acute myocardial infarction? Am J Epidemiol 1996;144:934-42.

[28] Hart CL, Hole DJ, Gillis CR, Davey Smith G, Watt GCM, Hawthorne VM. Social class differences in lung cancer mortality: risk factor explanations using two Scottish cohort studies. Int J Epidemiol 2001;30:268-74.

[29] Blane D, Davey Smith G, Bartley M. Social class differences in years of potential life lost: size, trends, and principal causes. Br Med J 1990;301:429-32.

[30] Brännström I, Weinehall L, Persson LA, Wester PO, Wall S. Changing social patterns of risk factors for cardiovascular disease in a Swedish community intervention programme. Int J Epidemiol 1993;22: 1026-37.

[31] Townsend J, Roderick P, Cooper J. Cigarette smoking by socioeconomic group, sex, and age: effects of price, income, and health publicity. Br Med J 1994;309:923-7.

[32] Platt S, Amos A, Gnich W, Parry O. Smoking policies. In: Mackenbach JP, Bakker MJ, editors. Reducing inequalities in health: the European perpective. London: Routledge; 2002. p. 124-43.

[33] Ogilvie D, Petticrew M. Reducing social inequalities in smoking: can evidence inform policy? A pilot study. Tob Control 2004;13:129-31.

[34] Whitehead M, Dahlgren G. What can be done about inequalities in health? Lancet 1991;338:1059-62. 